\title{
Self-reported sleeplessness in 12,655 persons living in the north of Norway: The Tromsø Study
}

\author{
Arne Fetveit ${ }^{1}$ \\ Jørund Straand ${ }^{1}$ \\ Bjørn Bjorvatn ${ }^{2,3}$ \\ Espen Saxhaug Kristoffersen ${ }^{4,5}$
}

\footnotetext{
${ }^{1}$ University of Oslo, General Practice Research Unit, Department of General Practice, Institute of Health and Society - Oslo - Norway.

${ }^{2}$ University of Bergen, Department of Global Public Health and Primary Care Bergen - Norway.

${ }^{3}$ Haukeland University Hospital, Norwegian Competence Center for Sleep Disorders - Bergen - Norway. ${ }^{4}$ University of Oslo, Department of General Practice - Oslo - Norway.

${ }^{5}$ Akershus University Hospital, Department of Neurology - Lørenskog - Norway.
}

\author{
Corresponding author: \\ Arne Fetveit. \\ E-mail: arne.fetveit@medisin.uio.no \\ Received: September 27, 2018; \\ Accepted: May 14, 2019.
}

\begin{abstract}
Sleep disturbances cause great impairment in quality of life. In this cross-sectional study, we analysed questionnaire-collected data from 12,655 persons (30-87 years) who participated in the sixth survey of the Tromsø Study carried out in 2007-2008. First, using this community-based sample representative of the general population of northern Norway, we performed a simple screening to identify individuals with self-reported sleeplessness among those survey participants who provided information about their sleep patterns. Self-reported sleeplessness was defined as responding "More than once a week" to the research question "How often have you suffered from sleeplessness during the last 12 months?" Second, we analysed the associations between selfreported sleeplessness and the following variables: age, gender, living with a spouse or not, level of education, employment status, income, smoking, alcohol consumption, body mass index, level of self-reported health, and psychological distress. Self-reported sleeplessness had a prevalence of $12.6 \%$ in this study population. For both men and women, the variables having the strongest association with sleeplessness were low levels of self-reported health (men, $\mathrm{OR}=8.70$; women, $\mathrm{OR}=5.73$ ) and the presence of psychological distress (men, $\mathrm{OR}=4.15$; women, $\mathrm{OR}=2.76$ ). In men, high levels of household income and education were both inversely related to the frequency of self-reported sleeplessness, while being unemployed was much more strongly associated with sleeplessness than being employed. We conclude that sleeplessness was frequent in this large population sample, affecting up to one in eight individuals. Subjects with self-reported sleeplessness had a distinctly different socio-economic profile and self-perceived health than those without complaints of sleeplessness.
\end{abstract}

Keywords: Sleep Initiation and Maintenance Disorders, Cross-Sectional Studies, Population Characteristics. 


\section{INTRODUCTION}

Insomnia symptoms are frequent health problems in the general adult population, in which approximately one-third complains about insomnia symptoms, while $10-20 \%$ meet the more stringent diagnostic criteria for chronic insomnia ${ }^{1}$. Insomnia symptoms generally increase with age $e^{2}$, and are more commonly reported by women than men ${ }^{3,4}$. The reasons for this gender difference are still unclear, but it is known that important biological events, often mediated by hormones and physiological changes, are associated with insomnia in women. ${ }^{5}$. Over the last decades, the reported prevalence of insomnia symptoms has risen steadily for both men and women ${ }^{6,7}$, and it is expected to increase even further in response to the ageing of the population ${ }^{8}$.

During the last decades there have established certain relationships between insomnia symptoms and medical as well as psychological health: Health-related quality of life is strongly influenced by insomnia symptoms ${ }^{9}$ and poor sleep has substantial negative economic impacts on both individuals and society $^{10,11}$. In Germany, Hajak ${ }^{12}$ found that severe degree of insomnia symptoms impaired individuals' perceived health even more than long-standing physical illness. Furthermore, strong associations have been reported between insomnia symptoms and poor mental health, psychological distress, anxiety, and depressive symptoms ${ }^{13,14}$, and patients with mood disorders have increased rates of primary sleep disorders, obstructive sleep apnoea (OSA), and daytime fatigue ${ }^{15}$. Other common determinants that are associated with insomnia symptoms include obesity, stress, poor perceived mental health, anxiety, psychiatric disorders, and low socioeconomic status ${ }^{16,17}$. In a large national survey from Finland, individuals who had low household income levels, were unemployed, or were disabled retirees were most likely to report poor sleep ${ }^{18}$.

Definitions of insomnia symptoms vary among studies $^{19}$. For the most part, inclusion criteria are neither uniform nor relate to prevailing diagnostic systems ${ }^{20,21}$. This might reflect both the difficulties in measuring sleep and the subjective nature of insomnia symptoms. Consequently, comparing results among studies with such varying definitions is often complicated. Rates of insomnia symptoms, without regard to specific sleep diagnosis, also vary across studies ${ }^{21}$. In a recent update of the European guidelines for insomnia ${ }^{1}$, it is stated that the diagnostic work-up for insomnia should include a clinical interview consisting of a sleep history (sleep habits, sleep environment, work schedules, circadian factors and impaired daytime functioning), the use of sleep questionnaires and sleep diaries, questions about somatic and mental health, a physical examination and additional measures if indicated. As the present study does not provide the necessary data to diagnose insomnia according to these guidelines, we found it appropriate to use the term "self-reported sleeplessness" to describe the sleep difficulties in this study. Findings from other studies with various methodology, also not in adherence to present guidelines for diagnosing insomnia, we chose to refer to as "insomnia symptoms".
The primary aim of this large population-based crosssectional study was to assess the prevalence of self-reported sleeplessness in a large and representative population sample in the north of Norway. A secondary aim was to analyse the possible associations between age, gender, living alone or with a spouse, level of education, employment status, income, smoking, alcohol consumption, body mass index (BMI), levels of self-reported health, and psychological distress on self-reported sleeplessness.

\section{METHODS}

\section{Participants and setting}

Population-based health surveys have been conducted in the municipality of Tromsø, in the north of Norway, since 1974. Tromsø is situated $70^{\circ}$ north of the equator and north of the Arctic Circle. It is the largest city in northern Norway, with approximately 60.000 inhabitants. The cross-sectional sixth Tromsø Study (Tromsø 6) was conducted from October 2007 to December 2008 and consisted of comprehensive questionnaires, clinical examination, and laboratory tests. Four groups were invited: 1$)$ every resident aged $40-42$ or $60-87$ years $(n=12,578)$, 2) a 10\% random sample of individuals aged $30-39(n=1,056)$, 3) a $40 \%$ random sample of people aged $43-59(n=5,787)$, and 4) all subjects who had attended the second visit of the previous Tromsø Study, if not already included in groups 1-3 $(\mathrm{n}=341)$. All participants received a postal study invitation and information, together with a self-administered questionnaire (Q1). The methods of Tromsø 6 have been described in detail elsewhere ${ }^{22}$.

\section{Self-reported sleeplessness}

In survey studies ${ }^{4,6}$, the presence of sleeplessness is typically defined by a positive response to a research question. Similarly, in this study, self-reported sleeplessness was defined as a participant response of "More than once a week" to the research question "How often have you suffered from sleeplessness during the last 12 months?" The frequency of self-reported sleeplessness was determined from the responses to that research question. Response options were: 1) "never, or just a few times a year", 2) "1-3 times a month, 3) "approximately once a week", and 4) "more than once a week". The study did not provide data on impaired daytime functioning, like excessive daytime sleepiness (EDS).

\section{Demographic background variables}

Independent variables were collected and included age (later recoded into 10-year age groups), marital status, the household's total gross income in the year prior to the study, highest education level attained, and employment status. The household's total gross income was originally divided into eight income response categories, but was later merged into four categories in terms of Norwegian kroner (NOK): low income (<200,000 NOK); low middle income (201,000-400,000 NOK); high middle income (401,000-700,000 NOK), and high income (>700,000 NOK) (1 NOK $\approx 0.1$ EUR). Three education 
response categories were created out of the original five: low (primary and part of secondary school), middle (high school), and high education (college or university). Employment status was self-reported by the participants as employed, unemployed, domestic, retired, or student. Smoking status (current, never, or previously) and frequency of drinking alcohol (never, monthly or less, two to four times monthly, two to three times weekly, or four times or more weekly) were assessed. BMI was calculated as weight divided by the square of height $\left(\mathrm{kg} / \mathrm{m}^{2}\right)$, as measured by study personnel in the Tromsø Study. BMI values were categorised as underweight (<18.5), normal (18.5-24.9), overweight (25-30), and obese $(>30)$.

\section{Self-rated health variables}

During analysis, response options for the self-rated health variable were reduced from originally five categories (very bad, bad, fair, good, or excellent) into four by merging the bad and very bad categories due to the low numbers in these two groups. Self-rated health compared to others of the same age was divided into three response categories (worse, equal, or better).

\section{Psychological distress}

Symptoms of psychological distress; specifically, symptoms of anxiety and depression, were measured using the short version of the Hopkins Symptom Check List-25 (SCL-25) ${ }^{23}$, referred to as the SCL- 5 . The SCL- 5 scale strongly correlates with the original SCL-25 scale $(\mathrm{r}=0.92)$, and been validated used as a screening measure of psychological distress in several studies $^{24-26}$. The SCL-25 corresponds well to DSM-IV-defined depression and anxiety disorders, phobia, and somatoform illness using the gold-standard Composite International Diagnostic Interview (CIDI) ${ }^{27}$. The SCL-5 has been validated in a Norwegian population ( $\geq 16$ years $)^{25}$, with a Cronbach's alpha of $0.85^{26}$. Compared with SCL-25, the SCL-5 has, in addition to reliability, good specificity $(82 \%)$ and sensitivity $(96 \%)$ to detect psychological distress ${ }^{25}$. The SCL-5 has five items: (1) feeling fearful, (2) nervousness or shakiness inside, (3) feeling hopeless about the future, (4) feeling blue, and (5) worrying too much about things. Each of the five items is scored on a scale of $1-4$, depending on how bothered the participants have been in that area in the 14 days prior to the time of self-report: $1=$ not bothered, $2=\mathrm{a}$ little bothered, $3=$ quite bothered, and $4=$ very bothered. The recommended cut-off score, indicating distress at case-level, is $\geq 2.0^{25}$.

\section{Statistics}

Multiple binary logistic regression analyses were used to examine the associations between self-reported sleeplessness and demographic background variables, self-rated health variables, and the level of psychological distress. The regression analyses were carried out in two steps: First, we performed an adjustment for gender and age (due to established gender and age differences in sleep and health). Second, subsequent binary logistic models were fitted to the data by adding selected socio- demographic factors in addition to age and gender until a full model was obtained. Model-fitting was performed using the forward-stepwise method, and the Akaike information criterion (AIC) was used to select the best model-fit ${ }^{28}$. The AIC was calculated during each stage of model-fitting, and among the set of candidate models, the one with the lowest AIC value was considered the best fit (Table 3). The analyses were done using StataSE 14 and the significance level was set at $\alpha=0.05$.

\section{RESULTS}

\section{Participants}

In total, 12,982 of the 19,762 invited persons aged 30 87 years participated, constituting a response rate of $65.7 \%$. This comprises approximately one-third (33.8\%) of the total population aged $30-87$ years in the Tromsø municipality. In the present study, a total of 12,655 respondents (6,741 women and 5,914 men) were included in the analyses, as 327 persons did not respond to the sleep screening question and were therefore excluded.

\section{Self-rated sleeplessness}

The response rate to the question: "How often have you suffered from sleeplessness during the last 12 months?" was $97.5 \%$. Of the 12,655 responders, $63.3 \%$ (54.5\% women and $73.4 \%$ men) reported suffering from sleeplessness "never, or just a few times a year", $17.4 \%$ (20.0\% women and 14.1\% men) reported " 1 -3 times a month", 6.7\% (8.5\% women and $4.3 \%$ men) reported "approximately once a week", and 12.6\% (17.0\% women and $8.2 \%$ men) reported sleeplessness "more than once a week", which was our indicator of self-reported sleeplessness.

The overall distribution of response frequencies related to self-reported sleeplessness was stratified for gender and reported for the following variables: age, marital status, smoking, alcohol consumption, household income, education level, employment status, self-rated health, self-rated health compared to others of the same age, and symptoms of psychological distress (Table 2). Self-reported sleeplessness increased gradually with each age group, in both men and women. The highest frequencies were found in the oldest age group (80-87 years), where $27.2 \%$ of women and $10.4 \%$ of men reported self-reported sleeplessness more than once a week.

\section{Sample characteristics}

For the whole sample $(n=12,655)$ the mean age for both men and women was 57.5 years. Approximately $75 \%$ of the sample population reported living with a partner or cohabitant. Of the sample, $38.2 \%$ had completed higher education, while $54.3 \%$ had only completed secondary school. More than half were in either full-time or part-time employment. Current smoking was reported by $21.3 \%$ of the women and $19.3 \%$ of the men. In addition, $20.3 \%$ of the women and $20.5 \%$ of the men were obese (defined as $\mathrm{BMI} \geq 30$ ) (Table 1).

In total, $5.5 \%, 28.6 \%, 51.3 \%$, and $14.6 \%$ reported bad or very bad, fair, good, and excellent self-rated health, respectively (Table 2). Respondents in the 60-69 years age group most 
Table 1. Sociodemographic data of the sample in the current study $(\mathrm{n}=12655)$. Data are shown in percentages and absolute numbers if not stated otherwise.

\begin{tabular}{|c|c|}
\hline \multicolumn{2}{|l|}{ Mean age in years } \\
\hline Female (SD) & $57.5(13.0)$ \\
\hline Male (SD) & $57.5(12.3)$ \\
\hline \multicolumn{2}{|l|}{ Age groups: } \\
\hline $30-39$ & $4.0(504)$ \\
\hline $40-49$ & $27.9(3531)$ \\
\hline $50-59$ & $18.9(2392)$ \\
\hline $60-69$ & $31.7(4005)$ \\
\hline $70-79$ & $13.7(1735)$ \\
\hline $80-87$ & $3.9(488)$ \\
\hline \multicolumn{2}{|l|}{ Living with a partner } \\
\hline Yes & $75.3(9246)$ \\
\hline No & $24.7(3031)$ \\
\hline \multicolumn{2}{|l|}{ Education: } \\
\hline Low $^{1}$ & $54.3(6790)$ \\
\hline Middle $^{2}$ & 7.5 (937) \\
\hline $\mathrm{High}^{3}$ & $38.2(4776)$ \\
\hline \multicolumn{2}{|l|}{ Employment status } \\
\hline Employed $^{4}$ & $58.2(7309)$ \\
\hline Unemployed & $0.8(99)$ \\
\hline Domestic work & $1.3(164)$ \\
\hline Retired & 38.8 (4918) \\
\hline Student & $0.9(111)$ \\
\hline \multicolumn{2}{|l|}{ Income } \\
\hline$<200000 \mathrm{NOK}$ & $11.9(1392)$ \\
\hline $201000-400000$ NOK & $26.5(3112)$ \\
\hline $401000-700000 \mathrm{NOK}$ & $35.5(4162)$ \\
\hline$>700000 \mathrm{NOK}$ & $26.1(3066)$ \\
\hline \multicolumn{2}{|l|}{ BMI } \\
\hline Mean in men (SD) & $27.3(3.8)$ \\
\hline Mean in women (SD) & $26.6(4.7)$ \\
\hline Underweight $^{5}$ & 0.6 \\
\hline Normal weight $^{6}$ & 34.7 \\
\hline Overweight $^{7}$ & 44.3 \\
\hline Obese $^{8}$ & 20.4 \\
\hline
\end{tabular}

1: primary and part of secondary school, 2: high school 3: college or university 4: full- or part-time work

5: BMI < 18.5, 6: BMI 18.5-24.9, 7: BMI 25.0-29.9, 8: BMI $\geq 30.0$

frequently reported their health as "bad or very bad" (32\%; females $29.5 \%$, males $35.7 \%$ ), while respondents in the $40-49$ years age group most frequently reported their health as "excellent" (41.3\%; females $43.6 \%$, males 38.3\%). Self-reported health as compared to others in the same age group, categorised as "worse", "equal", or "better", was rated most unfavourably by the 60-69 years age group, where 30.8\% (29.0\% females, 33.2\% males) regarded their health condition to be comparatively worse than that of others in the same age group.

The frequencies of psychological distress, defined as an SCL-5 score $\geq 2.0$ in age-strata by gender, ranged from $3.1 \%$ (males 80-87 years) to $9.1 \%$ (females 30-39 years) (Table 2).

\section{Multivariate analyses}

For both men and women, the strongest associations with self-reported sleeplessness were low levels of self-reported health (men, $\mathrm{OR}=8.70$; women, $\mathrm{OR}=5.73$ ) and an SCL-5 score $\geq 2.0$ as an indicator of psychological distress (men, $\mathrm{OR}=4.15$; women, $\mathrm{OR}=2.76$ ). For men, being unemployed compared to being employed was associated with self-reported sleeplessness $(\mathrm{OR}=2.47)$, as well as alcohol consumption for more than 2-3 times per week $(\mathrm{OR}=1.64)$ (Table 3$)$. In contrast, high levels of household income and education were both inversely related to the presence of self-reported sleeplessness in men (Table 3).

\section{DISCUSSION}

Self-reported sleeplessness was frequent with a prevalence of $12.6 \%$ in this large, population-based study. In multivariate logistic regression analyses, self-reported sleeplessness increased with age, poor socio-economic status, low levels of education, poor self-perceived health, and psychological distress.

In previous sleep studies, prevalence rates of insomnia symptoms vary widely, probably due to differences in study methods, study definitions of insomnia symptoms, and study population characteristics ${ }^{1,21,29}$. Population-based data from Europe seem to vary from a minimum of $5.7 \%$ in one Germany study to a maximum of $20 \%$ in one Norwegian study ${ }^{1,30-32}$. Studies in general practice (GP) settings report even higher prevalence: in Germany, Wittchen et al. ${ }^{33}$ reported that insomnia prevalence in GP patients were $26.5 \%$; whereas in Norway, Bjorvatn et al. ${ }^{34}$ found that more than $50 \%$ of GP patients suffered from insomnia, both studies based on the Diagnostic and Statistical Manual for Mental disorders (DSM)-version IV. In one previous Tromsø study (Tromsø II), a high prevalence of self-reported sleep dissatisfaction among 14,667 participants aged $20-54$ years was found; $41.7 \%$ females and $29.9 \%$ men responded yes to the question: "Are you bothered by sleeplessness?" 35 . However this study did not map the frequency of "sleeplessness" 35 .

In the present study, women reported more than twice as often self-reported sleeplessness as compared to men $(17.0 \%$ vs. $8.2 \%$ ). Female gender is a known risk factor for insomnia symptoms $^{36}$. In the large HUNT-2 population cohort study from Norway, $13.5 \%$ of participants reported insomnia symptoms and the prevalence was found to vary with age and gender, with the highest prevalence in older persons (80-89 years); older women were at a greater risk $(32 \%)$ compared to older men $(20 \%)^{37}$. In the present study, the greatest gender difference was found between older women and men (80-87 years) with a prevalence of self-reported sleeplessness of $27.2 \%$ in older women compared to $10.4 \%$ in older men. Observed differences in sleep between males and females are thought to begin in adolescence with the onset of menstruation and increased during menopause ${ }^{38}$. Still poorly understood, sleep regulation seems to be directly affected by endogenous oestrogens ${ }^{39}$. However, though physiological factors can potentially negatively impact sleep, they are unlikely to explain all aspects of gender differences in insomnia ${ }^{36}$. 
Table 2. Characteristics of participants stratified by gender and self-reported sleep quality ("How often have you suffered from sleeplessness the last 12 months?") in the Tromsø 6 study ( $\mathrm{n}=12$ 655). Percentages (\%) of sleep characteristics are given within each stratum.

\begin{tabular}{|c|c|c|c|c|c|c|c|c|c|c|}
\hline & \multicolumn{5}{|c|}{ Women } & \multicolumn{5}{|c|}{ Men } \\
\hline & $\begin{array}{c}\text { Total } \\
\text { sample (n) }\end{array}$ & $\begin{array}{c}\text { Never, or } \\
\text { just a few } \\
\text { times a } \\
\text { year }\end{array}$ & $1-3$ & $\begin{array}{l}\text { Approximately } \\
\text { once a week }\end{array}$ & $\begin{array}{c}\text { More than } \\
\text { once a } \\
\text { week }\end{array}$ & $\begin{array}{c}\text { Total } \\
\text { sample } \\
\text { (n) }\end{array}$ & $\begin{array}{c}\text { Never, or } \\
\text { just a few } \\
\text { times a } \\
\text { year }\end{array}$ & $\begin{array}{l}\text { 1-3 times a } \\
\text { month }\end{array}$ & $\begin{array}{l}\text { Approximately } \\
\text { once a week }\end{array}$ & $\begin{array}{c}\text { More than } \\
\text { once a week }\end{array}$ \\
\hline \multicolumn{11}{|l|}{ Age (years) } \\
\hline $30-39$ & 295 & 65.8 & 16.3 & 8.5 & 9.5 & 209 & 76.1 & 12.9 & 5.3 & 5.7 \\
\hline $40-49$ & 1888 & 64.9 & 18.3 & 6.3 & 10.4 & 1643 & 74.7 & 14.9 & 3.7 & 6.8 \\
\hline $50-59$ & 1265 & 53.0 & 22.0 & 8.7 & 16.3 & 1127 & 71.3 & 14.2 & 4.8 & 9.7 \\
\hline $60-69$ & 2051 & 49.4 & 21.5 & 9.6 & 19.5 & 1954 & 74.1 & 13.2 & 4.6 & 8.2 \\
\hline $70-79$ & 937 & 47.8 & 17.6 & 9.6 & 25.0 & 798 & 71.3 & 14.5 & 5.1 & 9.0 \\
\hline $80-87$ & 305 & 38.7 & 22.3 & 11.8 & 27.2 & 183 & 72.1 & 15.3 & 2.2 & 10.4 \\
\hline Total n & 6741 & & & & & 5914 & & & & \\
\hline \multicolumn{11}{|l|}{ Marital status } \\
\hline \multicolumn{11}{|l|}{ Married/ } \\
\hline cohabitant & 4475 & 56.3 & 20.6 & 8.2 & 14.9 & 4771 & 75.5 & 13.2 & 4.2 & 7.0 \\
\hline Single & 1996 & 50.2 & 19.6 & 9.5 & 20.7 & 1035 & 63.5 & 17.8 & 5.3 & 13.4 \\
\hline Total n & 6471 & & & & & 5806 & & & & \\
\hline \multicolumn{11}{|l|}{ Smoking } \\
\hline Never & 2678 & 57.4 & 19.9 & 8.4 & 14.4 & 1128 & 77.0 & 13.3 & 4.0 & 5.7 \\
\hline Yes, now & 1414 & 51.5 & 18.7 & 8.2 & 21.6 & 2733 & 68.9 & 15.6 & 5.0 & 10.5 \\
\hline Previously & 2541 & 53.5 & 21.0 & 9.1 & 16.6 & 1990 & 72.6 & 14.1 & 4.4 & 10.5 \\
\hline Total n & 6633 & & & & & 5851 & & & & \\
\hline \multicolumn{11}{|l|}{ Alcohol } \\
\hline Never & 943 & 50.2 & 18.1 & 8.5 & 23.2 & 449 & 72.8 & 13.1 & 3.3 & 10.7 \\
\hline Never & 943 & 50.2 & 18.1 & 8.5 & 23.2 & 449 & 72.8 & 13.1 & 3.3 & 10.7 \\
\hline 2-4 times/month & 2338 & 55.4 & 20.8 & 8.9 & 15.0 & 2439 & 74.7 & 14.4 & 4.2 & 6.7 \\
\hline 2-3 times/week & 1016 & 53.4 & 22.6 & 9.1 & 14.9 & 1115 & 70.4 & 15.4 & 5.3 & 8.9 \\
\hline$>4$ times/week & 290 & 54.8 & 20.7 & 7.2 & 17.2 & 339 & 67.6 & 13.0 & 5.9 & 13.6 \\
\hline Total n & 6643 & & & & & & 5867 & & & \\
\hline \multicolumn{11}{|l|}{ Household income } \\
\hline Low $^{1}$ & 952 & 42.5 & 20.6 & 10.2 & 26.7 & 440 & 65.2 & 14.3 & 4.5 & 15.5 \\
\hline Low middle $^{2}$ & 1750 & 51.2 & 20.5 & 9.5 & 18.9 & 1362 & 70.2 & 13.8 & 4.6 & 11.5 \\
\hline High middle ${ }^{3}$ & 1944 & 56.1 & 21.7 & 8.0 & 14.2 & 2218 & 74.8 & 13.9 & 4.0 & 6.8 \\
\hline High $^{4}$ & 1414 & 64.9 & 19.2 & 7.0 & 8.9 & 1652 & 76.6 & 14.5 & 4.4 & 5.0 \\
\hline Total n & 6060 & & & & & 5672 & & & & \\
\hline \multicolumn{11}{|l|}{ Education } \\
\hline Low $^{5}$ & 3699 & 50.5 & 19.4 & 9.1 & 21.0 & 3091 & 73.2 & 13.3 & 4.2 & 9.3 \\
\hline Middle $^{6}$ & 517 & 58.0 & 19.9 & 5.0 & 17.0 & 420 & 74.5 & 15.5 & 2.6 & 7.4 \\
\hline $\mathrm{High}^{7}$ & 2441 & 60.1 & 21.0 & 8.4 & 10.5 & 2335 & 73.7 & 14.9 & 4.8 & 6.5 \\
\hline Total n & 6657 & & & & & 5846 & & & & \\
\hline \multicolumn{11}{|l|}{ Employment status } \\
\hline Employed $^{8}$ & 3676 & 62.3 & 19.9 & 7.4 & 10.4 & 3633 & 76.3 & 13.7 & 4.0 & 6.1 \\
\hline Unemployed & 42 & 38.1 & 28.6 & 7.1 & 26.2 & 57 & 45.6 & 22.8 & 8.8 & 22.8 \\
\hline Domestic & 145 & 53.1 & 26.2 & 5.5 & 15.2 & 19 & 57.9 & 10.5 & 5.3 & 26.3 \\
\hline Retired & 2726 & 44.2 & 19.8 & 10.3 & 25.6 & 2142 & 69.7 & 14.5 & 4.8 & 11.1 \\
\hline Student & 84 & 59.5 & 14.3 & 9.5 & 16.7 & 27 & 51.9 & 14.8 & 22.2 & 11.1 \\
\hline Total n & 6673 & & & & & 5878 & & & & \\
\hline \multicolumn{11}{|l|}{ Self-rated health } \\
\hline Bad & 406 & 23.9 & 18.0 & 12.6 & 45.6 & 283 & 38.9 & 20.8 & 9.2 & 31.1 \\
\hline Fair & 1945 & 39.9 & 21.5 & 11.4 & 27.2 & 1644 & 62.9 & 17.0 & 7.1 & 13.1 \\
\hline
\end{tabular}

Sleep Sci. 2019;12(3):147-155 
Continuation Table 2.

\begin{tabular}{|c|c|c|c|c|c|c|c|c|c|c|}
\hline Good & 3296 & 60.2 & 20.7 & 7.8 & 11.3 & 3146 & 78.9 & 12.8 & 3.2 & 5.1 \\
\hline Excellent & 1036 & 75.8 & 15.4 & 4.3 & 4.4 & 811 & 85.2 & 10.6 & 2.0 & 2.2 \\
\hline Total n & 6683 & & & & & 5884 & & & & \\
\hline \multicolumn{11}{|c|}{$\begin{array}{l}\text { Self-rated health } \\
\text { compared to others } \\
\text { of same age }\end{array}$} \\
\hline Worse & 998 & 32.9 & 19.8 & 11.7 & 35.6 & 726 & 49.4 & 19.1 & 8.5 & 22.9 \\
\hline Equal & 3786 & 56.1 & 20.7 & 8.3 & 14.9 & 3099 & 74.6 & 14.2 & 4.4 & 6.8 \\
\hline Better & 1734 & 63.5 & 18.9 & 7.2 & 10.5 & 2005 & 79.9 & 12.0 & 3.0 & 5.0 \\
\hline Total $\mathrm{n}$ & 6518 & & & & & 5830 & & & & \\
\hline \multicolumn{11}{|l|}{$\begin{array}{l}\text { Psychological } \\
\text { distress }\end{array}$} \\
\hline No distress & 6260 & 57.0 & 19.8 & 8.2 & 15.0 & 5642 & 75.5 & 13.7 & 4.0 & 6.8 \\
\hline Distress & 481 & 21.0 & 22.5 & 12.7 & 43.9 & 272 & 28.3 & 22.4 & 13.6 & 35.7 \\
\hline Total n & 6741 & & & & & 5914 & & & & \\
\hline \multicolumn{11}{|l|}{ BMI } \\
\hline Underweight ${ }^{9}$ & 63 & 52.4 & 15.9 & 7.9 & 23.8 & 17 & 76.5 & 11.8 & 5.9 & 5.9 \\
\hline Normal weight ${ }^{10}$ & 2724 & 56.1 & 20.0 & 8.5 & 15.5 & 1653 & 72.6 & 14.8 & 4.1 & 8.5 \\
\hline Overweight $^{11}$ & 2570 & 53.3 & 20.2 & 8.8 & 17.7 & 3018 & 74.7 & 14.1 & 4.0 & 7.2 \\
\hline Obese $^{12}$ & 1359 & 53.8 & 19.3 & 8.5 & 18.5 & 1212 & 71.0 & 13.2 & 5.6 & 10.1 \\
\hline Total $n$ & 6716 & & & & & 5900 & & & & \\
\hline
\end{tabular}

Although comparisons with other epidemiological studies are difficult because target population, methodology and insomnia definitions are not the same, we found that the overall prevalence of self-reported sleeplessness increased with age, in accordance with most previous epidemiologic studies ${ }^{1,40}$. However, some recent studies have produced mixed results, some studies even report higher prevalence of insomnia in younger versus older age groups ${ }^{32,34}$. Sleep maintenance difficulties are more common among middle-aged and older adults, whereas sleep initiation difficulties are more frequent among younger adults $^{13}$. Whereas insomnia symptoms in general, particularly sleep fragmentation, increase with age $e^{41}$, some reports show that complaints of daytime impairment decline with advancing age $^{42,43}$. This discrepancy is not fully understood but may indicate an age-related tolerance to sleep disturbances.

The present study measures subjective "sleeplessness". We believe that this measure is clinically relevant, as insomnia is principally a subjective diagnosis based on data obtained from the patient, by a clinical interview and/or a questionnaire. The other principal methodologies for assessing sleep employ socalled objective measurements and include polysomnography (PSG) and actigraphy. It would not, however, be feasible to test all participants in large population studies with such instruments. One must also keep in mind the possibility that a positive response to a question of sleeplessness may be influenced by other features, like depression or pain, both known to increase with age. Sivertsen et al. ${ }^{44}$ reported that sleep parameters in the present study population were significantly associated with reduced pain tolerance, and that both the frequency and severity of insomnia, in addition to sleep onset problems and sleep efficiency, were associated with pain sensitivity in a dose-response manner.
The prevalence of self-reported sleeplessness of $12.6 \%$ found in the present study seems to harmonise well with the findings of other large population studies, and it is interesting that one simple screening question for self-reported sleeplessness seems to give comparable results to other large community-samples using different, more complex screening tools ${ }^{29,38}$. However, to use validated and comprehensive questionnaires are still recommended when feasible.

The association between self-reported sleeplessness and high psychological distress found in this study is also in concordance with previous studies ${ }^{14,45}$. Our study shows a strong association between poor self-perceived health and self-reported sleeplessness. Self-rated poor health status has been associated with insomnia symptoms in a large number of studies ${ }^{46,47}$. Our analysis suggests that the differences in health status between men and women do not explain the gender difference in sleep problems. Indeed, the gender difference becomes even greater after adjusting for health variables and psychological distress. It remains challenging to determine whether a factor like selfreported poor health meets the criteria for a true risk factor, or whether it acts through the intermediary pathway of other risk factors ${ }^{48}$.

Our research supports other studies that have found more sleep complaints among individuals with lower education levels. This association may reflect the results of previous studies that daytime sleepiness negatively affects high school students, and that both sleep onset and maintenance insomnia are significantly correlated with poorer school performance among college students ${ }^{49}$. A dose-response relationship between education level and insomnia symptoms seems to exist, even after being controlled for gender and age $\mathrm{e}^{50}$. A hypothesis presented by Winkleby et al. ${ }^{51}$ implies that psychological distress could play 
Table 3. Multiple binary logistic regression analysis was used to examine the association between socio-demographic factors and insomnia (sleeplessness more than once a week) in men and women. Model-fitting was performed using the forward-stepwise method, and the Akaike Information Criterion (AIC) was used to select the best model fit. Figures are odds ratios (OR) with $95 \%$ confidence intervals (CI). Significant results at $\alpha=5 \%(*)$ and at $\alpha=1 \%(* *)$.

\begin{tabular}{|c|c|c|}
\hline & Men & Women \\
\hline OR $(95 \% \mathrm{CI})$ & OR $(95 \% \mathrm{CI})$ & \\
\hline Referent age group: $30-39$ years & 1.00 & 1.00 \\
\hline $40-49$ & $0.86(0.45,1.65)$ & $1.00(0.63,1.60)$ \\
\hline $50-59$ & $1.10(0.57,2.13)$ & $1.56(0.97,2.51)$ \\
\hline $60-69$ & $0.76(0.38,1.49)$ & $1.53(0.94,2.48)$ \\
\hline $70-79$ & $0.70(0.33,1.49)$ & $1.82(1.07,3.09)^{*}$ \\
\hline $80-87$ & $0.53(0.20,1.41)$ & $1.41(0.75,2.64)$ \\
\hline Spouse: Yes & 1.00 & 1.00 \\
\hline No & $1.35(1.02,1.80)^{*}$ & $1.23(1.00,1.50)^{*}$ \\
\hline Referent smoking status: Never smoked & 1.00 & 1.00 \\
\hline Current smokers & $1.17(0.85,1.60)$ & $1.37(1.11,1.70)^{* *}$ \\
\hline Previous smokers & $1.25(0.96,1.63)$ & $1.16(0.96,1.39)$ \\
\hline Referent drinking habits: Never & 1.00 & 1.00 \\
\hline Monthly or less frequently & $1.03(0.66,1.60)$ & $0.87(0.68,1.12)$ \\
\hline $2-4$ times a month & $1.16(0.75,1.79)$ & $0.89(0.69,1.15)$ \\
\hline $2-3$ times a week & $1.64(1.03,2.60)^{*}$ & $1.00(0.74,1.36)$ \\
\hline 4 or more times a week & $2.94(1.72,5.03)^{* *}$ & $1.30(0.84,1.99)$ \\
\hline Referent health status: Excellent & 1.00 & 1.00 \\
\hline Good & $2.42(1.41,1.18)^{* *}$ & $1.97(1.39,2.81)^{* *}$ \\
\hline Fair & $5.25(2.92,9.43)^{* *}$ & $3.91(2.67,5.72)^{* *}$ \\
\hline $\mathrm{Bad}$ & $8.70(4.36,17.34)^{* *}$ & $5.73(3.52,9.33)^{* *}$ \\
\hline Health compared: Better & 1.00 & 1.00 \\
\hline The same & $1.32(0.88,2.00)$ & $1.13(0.91,1.42)^{*}$ \\
\hline Worse & $0.75(0.58,1.05)$ & $1.63(1.19,2.24)^{* *}$ \\
\hline Psychological distress: (No distress) & 1.00 & 1.00 \\
\hline Distress & $4.15(3.01,5.71)^{* *}$ & $2.76(2.17,3.50)^{* *}$ \\
\hline Education: High & 1.00 & 1.00 \\
\hline Middle & $0.98(0.63,1.52)$ & $1.40(1.03,1.91)^{* *}$ \\
\hline Low & $1.07(0.83,1.38)$ & $1.32(1.08,1.64)^{* *}$ \\
\hline Employment status: Employed & 1.00 & 1.00 \\
\hline Unemployed & $2.47(1.14,5.37)^{*}$ & $1.80(0.81,4.03)$ \\
\hline Domestic work & $2.69(0.60,12.14)$ & $0.69(0.35,1.35)$ \\
\hline Retired & $1.30(0.95,1.80)$ & $1.53(1.22,1.93)^{* *}$ \\
\hline Student & $1.03(0.28,3.79)$ & $1.93(0.98,3.79)$ \\
\hline Income: >700000 NOK & 1.00 & 1.00 \\
\hline $401000-700000 \mathrm{NOK}$ & $1.15(0.84,1.58)$ & $0.96(0.74,1.24)$ \\
\hline $201000-400000$ NOK & $1.51(1.03,2.22)^{*}$ & $0.94(0.70,1.29)$ \\
\hline$<200000$ & $1.91(1.13,3.24)^{*}$ & $0.89(0.61,1.29)$ \\
\hline BMI: Normal weight & 1.00 & 1.00 \\
\hline Underweight & $0.42(0.48,3.96)$ & $1.54(0.71,3.36)$ \\
\hline Overweight & $0.82(0.63,1.05)$ & $0.99(0.82,1.17)$ \\
\hline Obese & $0.97(0.72,1.31)$ & $0.89(0.71,1.10)$ \\
\hline AIC & 2623.28 & 4260.60 \\
\hline
\end{tabular}

a role in the relationship between education level and insomnia symptoms. In other words, Winkleby et al. ${ }^{51}$ argue that education may serve to protect against insomnia by influencing lifestyle behaviours and problem-solving abilities, and by facilitating the acquisition of positive social, psychological, and economic skills and assets that may provide insulation from adverse influences.

Consistently in our study, more cases of self-reported sleeplessness were reported among the elderly, men drinking 
alcohol $\geq 2$-3 times per week, unemployed men, and those with symptoms of psychological distress. In contrast, less selfreported sleeplessness was reported by non-smokers, those employed and those with high levels of education and income, as well as those with no symptoms of psychological distress.

Although much of the research on sleep and psychological problems conducted in recent years has focused on depression, sleep disturbances have been documented to occur with high prevalence in patients with a variety of psychiatric disorders ${ }^{52}$. The SCL- 5 score used in the present study does not provide a diagnosis; it merely indicates a certain level of men$\mathrm{tal} /$ psychological distress or worry and rumination, which are features of a variety of psychiatric disorders. However, it is established that even worries and ruminations, not necessarily accompanied by a psychiatric diagnosis, do represent an important predictor of sleep problems ${ }^{53,54}$. One diagnostic contradiction is that patients who are diagnosed with a mental disorder are almost never diagnosed with insomnia ${ }^{55}$. Underlying this may be the long-standing consideration whether insomnia should be regarded as a symptom of other disorders or as a disorder itself.

The present study was conducted in The Norwegian city of Tromsø, which is situated $70^{\circ}$ north of the equator and north of the Arctic Circle. The term "midwinter insomnia" has been applied for the seasonal type of insomnia observed in arctic areas during the dark periods of the year ${ }^{56}$. In two previous studies by Johnsen et al. ${ }^{57,58}$ from the same population as the present (Tromsø VI), the possible effect of seasonal changes in daytime light exposure on sleep was explored and it was found a significant advance in the sleep-wake rhythm during the summer period, but of only 8 minutes ${ }^{57}$. The present study did not have data to sufficiently map seasonal variations, as we measured selfreported sleeplessness during the past 12 months. However, the prevalence of $12.6 \%$ self-reported sleeplessness found in this study is on the same level as in similar studies from southern/ non-arctic parts of Norway ${ }^{32,59}$.

A strength of the present study was the high number of attendees. All adults in the municipality of Tromsø, aged 3087 years, were invited. Of the 12,982 persons enrolled in the Tromsø study, 12,655 responded to the sleep screening question and were included in the present study. The Tromsø Study has a very high attendance rate even throughout repeated assessments during 30 years, and the study design has been evaluated throughout these years. Another strength of the Tromsø Study is the wide range of conditions that are assessed. Limitations in this study include the fact that the cross-sectional design restricts the possibility of cause-effect conclusions. Further, that the data were collected at one single occasion, so that possible seasonal variations of sleep may have influenced the results, as well as the possibility for recall bias. Another limitation was the lack of validated insomnia assessment, including evaluation of daytime consequences of the sleeplessness.

\section{CONCLUSION}

This study demonstrated that there was strong linkage both between socio-economic variables and reported sleep problems and between self-perceived health and reported sleep problems.

\section{REFERENCES}

1. Riemann D, Baglioni C, Bassetti C, Bjorvatn B, Dolenc Groselj L, Ellis JG, et al. European guideline for the diagnosis and treatment of insomnia. J Sleep Res. 2017;26(6):675-700.

2. Pandi-Perumal SR, Seils LK, Kayumov L, Ralph MR, Lowe A, Moller $\mathrm{H}$, et al. Senescence, sleep, and circadian rhythms. Ageing Res Rev. 2002;1(3):559-604.

3. Knutson KL. Sociodemographic and cultural determinants of sleep deficiency: implications for cardiometabolic disease risk. Soc Sci Med. 2013;79:7-15.

4. Ohayon MM, Sagales T. Prevalence of insomnia and sleep characteristics in the general population of Spain. Sleep Med. 2010;11(10):1010-8.

5. Nowakowski S, Meers J, Heimbach E. Sleep and Women's Health. Sleep Med Res. 2013;4(1):1-22.

6. Talala KM, Martelin TP, Haukkala AH, Härkänen TT, Prättälä RS. Socioeconomic differences in self-reported insomnia and stress in Finland from 1979 to 2002: a population-based repeated cross-sectional survey. BMC Public Health. 2012;12:650.

7. Pallesen S, Sivertsen B, Nordhus IH, Bjorvatn B. A 10-year trend of insomnia prevalence in the adult Norwegian population. Sleep Med. 2014;15(2):173-9.

8. Ferrie JE, Kumari M, Salo P, Singh-Manoux A, Kivimäki M. Sleep epidemiology--a rapidly growing field. Int J Epidemiol. 2011;40(6):1431-7.

9. Kyle SD, Morgan K, Espie CA. Insomnia and health-related quality of life. Sleep Med Rev. 2010;14(1):69-82.

10. Léger D, Bayon V. Societal costs of insomnia. Sleep Med Rev. 2010;14(6):379-89.

11. Rosekind MR, Gregory KB. Insomnia risks and costs: health, safety, and quality of life. Am J Manag Care. 2010;16(8):617-26.

12. Hajak G; SINE Study Group. Study of Insomnia in Europe. Epidemiology of severe insomnia and its consequences in Germany. Eur Arch Psychiatry Clin Neurosci. 2001;251(2):49-56.

13. Morin CM, Drake CL, Harvey AG, Krystal AD, Manber R, Riemann D, et al. Insomnia disorder. Nat Rev Dis Primers. 2015;1:15026.

14. Roth T, Jaeger S, Jin R, Kalsekar A, Stang PE, Kessler RC. Sleep problems, comorbid mental disorders, and role functioning in the national comorbidity survey replication. Biol Psychiatry. 2006;60(12):1364-71.

15. Klink M, Quan SF. Prevalence of reported sleep disturbances in a general adult population and their relationship to obstructive airways diseases. Chest. 1987;91(4):540-6.

16. Sivertsen B, Skogen JC, Jakobsen R, Hysing M. Sleep and use of alcohol and drug in adolescence. A large population-based study of Norwegian adolescents aged 16 to 19 years. Drug Alcohol Depend. 2015;149:180-6.

17. Palm A, Janson C, Lindberg E. The impact of obesity and weight gain on development of sleep problems in a population-based sample. Sleep Med. 2015;16(5):593-7.

18. Lallukka T, Sares-Jäske L, Kronholm E, Sääksjärvi K, Lundqvist A, Partonen $\mathrm{T}$, et al. Sociodemographic and socioeconomic differences in sleep duration and insomnia-related symptoms in Finnish adults. BMC Public Health. 2012;12:565.

19. Taylor DJ, Lichstein KL, Durrence HH. Insomnia as a Health Risk Factor Behavioral Sleep Medicine: Lawrence Erlbaum Associates; 2003. p. 227-47.

20. Martin JL, Ancoli-Israel S. Assessment and diagnosis of insomnia in nonpharmacological intervention studies. Sleep Med Rev. 2002;6(5):379-406.

21. Ohayon MM. Epidemiology of insomnia: what we know and what we still need to learn. Sleep Med Rev. 2002;6(2):97-111.

22. Jacobsen BK, Eggen AE, Mathiesen EB, Wilsgaard T, Niølstad I. Cohort profile: the Tromso Study. Int J Epidemiol. 2012;41(4):961-7.

23. Hesbacher PT, Rickels K, Morris RJ, Newman H, Rosenfeld H. Psychiatric illness in family-practice. J Clin Psychiatry. 1980;41(1):6-10.

24. Derogatis LR, Lipman RS, Rickels K, Uhlenhuth EH, Covi L. The Hopkins Symptom Checklist (HSCL): a self-report symptom inventory. Behav Sci. 1974;19(1):1-15.

25. Strand BH, Dalgard OS, Tambs K, Rognerud M. Measuring the mental health status of the Norwegian population: a comparison of the instruments SCL25, SCL-10, SCL-5 and MHI-5 (SF-36). Nord J Psychiatry. 2003;57(2):113-8.

26. Tambs K, Moum T. How well can a few questionnaire items indicate anxiety and depression? Acta Psychiatr Scand. 1993;87(5):364-7.

27. Sandanger I, Moum T, Ingebrigtsen G, Dalgard OS, Sørensen T, Bruusgaard D. Concordance between symptom screening and diagnostic procedure: the Hopkins Symptom Checklist-25 and the Composite International Diagnostic Interview I. Soc Psychiatry Psychiatr Epidemiol. $1998 ; 33(7): 345-54$ 
28. Vrieze SI. Model selection and psychological theory: a discussion of the differences between the Akaike information criterion (AIC) and the Bayesian information criterion (BIC). Psychol Methods. 2012;17(2):22843.

29. Ohayon MM. Prevalence and correlates of nonrestorative sleep complaints. Arch Intern Med. 2005;165(1):35-41.

30. Leger D, Guilleminault C, Dreyfus JP, Delahaye C, Paillard M. Prevalence of insomnia in a survey of 12,778 adults in France. J Sleep Res. 2000;9(1):35-42.

31. Schlack R, Hapke U, Maske U, Busch M, Cohrs S. [Frequency and distribution of sleep problems and insomnia in the adult population in Germany: results of the German Health Interview and Examination Survey for Adults (DEGS1)]. Bundesgesundheitsblatt Gesundheitsforschung Gesundheitsschutz. 2013;56(5-6):740-8.

32. Bjorvatn $B$, Waage $S$, Pallesen $S$. The association between insomnia and bedroom habits and bedroom characteristics: an exploratory crosssectional study of a representative sample of adults. Sleep Health. 2018;4(2):188-93.

33. Wittchen HU, Krause P, Höfler M, Pittrow D, Winter S, Spiegel B, et al. [NISAS-2000: The "Nationwide Insomnia Screening and Awareness Study". Prevalence and interventions in primary care]. Fortschr Med Orig. 2001;119(1):9-19.

34. Bjorvatn B, Meland E, Flo E, Mildestvedt T. High prevalence of insomnia and hypnotic use in patients visiting their general practitioner. Fam Pract. 2017;34(1):20-4.

35. Husby R, Lingjaerde O. Prevalence of reported sleeplessness in northern Norway in relation to sex, age and season. Acta Psychiatr Scand. 1990;81(6):542-7.

36. Theorell-Haglöw J, Miller CB, Bartlett DJ, Yee BJ, Openshaw HD, Grunstein RR. Gender differences in obstructive sleep apnoea, insomnia and restless legs syndrome in adults - What do we know? A clinical update. Sleep Med Rev. 2018;38:28-38.

37. Sivertsen B, Salo P, Mykletun A, Hysing M, Pallesen S, Krokstad S, et al. The bidirectional association between depression and insomnia: the HUNT study. Psychosom Med. 2012;74(7):758-65.

38. Johnson EO, Roth T, Schultz L, Breslau N. Epidemiology of DSM-IV insomnia in adolescence: lifetime prevalence, chronicity, and an emergent gender difference. Pediatrics. 2006;117(2):e247-56.

39. Pengo MF, Won CH, Bourjeily G. Sleep in Women Across the Life Span. Chest. 2018;154(1):196-206.

40. Li J, Vitiello MV, Gooneratne NS. Sleep in Normal Aging. Sleep Med Clin. 2018;13(1):1-11

41. Ohayon MM, Carskadon MA, Guilleminault C, Vitiello MV. Meta-analysis of quantitative sleep parameters from childhood to old age in healthy individuals: developing normative sleep values across the human lifespan. Sleep. 2004;27(7):1255-73.

42. Roth T, Coulouvrat C, Hajak G, Lakoma MD, Sampson NA, Shahly V, et al. Prevalence and perceived health associated with insomnia based on DSM-IV-TR; International Statistical Classification of Diseases and Related Health Problems, Tenth Revision; and Research Diagnostic Criteria/International Classification of Sleep Disorders, Second Edition criteria: results from the America Insomnia Survey. Biol Psychiatry. 2011;69(6):592-600.
43. Pillai V, Roth T, Mullins HM, Drake CL. Moderators and mediators of the relationship between stress and insomnia: stressor chronicity, cognitive intrusion, and coping. Sleep. 2014;37(7):1199-208.

44. Sivertsen B, Lallukka T, Petrie KJ, Steingrímsdóttir ÓA, Stubhaug A, Nielsen CS. Sleep and pain sensitivity in adults. Pain. 2015;156(8):1433-9.

45. Breslau N, Roth T, Rosenthal L, Andreski P. Sleep disturbance and psychiatric disorders: a longitudinal epidemiological study of young adults. Biol Psychiatry. 1996;39(6):411-8.

46. Whinnery J, Jackson N, Rattanaumpawan P, Grandner MA. Short and long sleep duration associated with race/ethnicity, sociodemographics, and socioeconomic position. Sleep. 2014;37(3):601-11.

47. Grandner MA, Martin JL, Patel NP, Jackson NJ, Gehrman PR, Pien G et al. Age and sleep disturbances among American men and women: data from the U.S. Behavioral Risk Factor Surveillance System. Sleep. 2012;35(3):395-406.

48. Kraemer HC, Stice E, Kazdin A, Offord D, Kupfer D. How do risk factors work together? Mediators, moderators, and independent, overlapping, and proxy risk factors. Am J Psychiatry. 2001;158(6):848-56.

49. Pagel JF, Kwiatkowski CF. Sleep complaints affecting school performance at different educational levels. Front Neurol. 2010;1:125.

50. Gellis LA, Lichstein KL, Scarinci IC, Durrence HH, Taylor DJ, Bush AJ, et al. Socioeconomic status and insomnia. J Abnorm Psychol. 2005;114(1):111-8

51. Winkleby MA, Jatulis DE, Frank E, Fortmann SP. Socioeconomic status and health: how education, income, and occupation contribute to risk factors for cardiovascular disease. Am J Public Health. 1992;82(6):816-20.

52. Winokur A. The Relationship Between Sleep Disturbances and Psychiatric Disorders: Introduction and Overview. Psychiatr Clin North Am. 2015;38(4):603-14.

53. Carney CE, Harris AL, Moss TG, Edinger JD. Distinguishing rumination from worry in clinical insomnia. Behav Res Ther. 2010;48(6):540-6.

54. Harvey AG, Greenall E. Catastrophic worry in primary insomnia. J Behav Ther Exp Psychiatry. 2003;34(1):11-23.

55. Kallestad H, Hansen B, Langsrud K, Ruud T, Morken G, Stiles TC, et al. Differences between patients' and clinicians' report of sleep disturbance: a field study in mental health care in Norway. BMC Psychiatry. 2011;11:186.

56. Lingjaerde O, Bratlid T, Hansen T. Insomnia during the "dark period" in northern Norway. An explorative, controlled trial with light treatment. Acta Psychiatr Scand. 1985;71(5):506-12.

57. Johnsen MT, Wynn R, Allebrandt K, Bratlid T. Lack of major seasonal variations in self reported sleep-wake rhythms and chronotypes among middle aged and older people at 69 degrees North: the Tromsø Study. Sleep Med. 2013;14(2):140-8.

58. Johnsen MT, Wynn R, Bratlid T. Is there a negative impact of winter on mental distress and sleeping problems in the subarctic: the Tromsø Study. BMC Psychiatry. 2012;12:225.

59. Uhlig BL, Sand T, Odegård SS, Hagen K. Prevalence and associated factors of DSM-V insomnia in Norway: the Nord-Trondelag Health Study (HUNT 3). Sleep Med. 2014;15(6):708-13. 